\title{
DIFERENTES ADUBAÇÕES NA CULTURA DO FEIJÃO GUANDU
}

Thadeu Henrique Novais Spósito ${ }^{1}$, Lucas Pedro Barbosa ${ }^{2}$, Natalia Frizzeira ${ }^{3}$, Luciana Boulhosa Fabris $^{4}$.

${ }^{1}$ Universidade Estadual Paulista - UNESP, Doutorando. ${ }^{2}$ Etec Dr Antonio Eufrásio de Toledo. ${ }^{3}$ Faculdade de Ciências Agrárias de Andradina - FCAA. ${ }^{4}$ Universidade do Oeste Paulista - UNOESTE, Doutoranda.

\section{RESUMO}

O presente trabalho tem o objetivo de analisar a produtividade, a altura e a composição bromatológica da cultura do feijão guandu com adubação química e orgânica. $O$ experimento foi realizado na ETEC Prof. Dr. Antonio Eufrásio de Toledo e instalado com três tratamentos: T1: Adubação química com Super Fosfato Simples; T2: Adubação Orgânica com Esterco de bovinos; e T3: Testemunha, com quatro repetições em blocos casualizados. As parcelas foram demarcadas com $2 \mathrm{~m}^{2}$ cada. Aos 120 dias foi coletado 0,50 m de cada parcela para análise da produtividade, altura e formação da amostra para análise bromatológica. Verificou-se por meio de estatística que não houve influência significativa nos diferentes tratamentos.

Palavras-chave: Cajanus cajan; produtividade de matéria seca; proteína bruta.

\section{DIFFERENT FERTILIZERS IN THE BEAN CULTURE GUANDU}

\begin{abstract}
The present work has the objective of analyzing the productivity, the height and the bromatological composition of the pigeon pea crop with chemical and organic fertilization. The experiment was performed at ETEC Prof. Dr. Antonio Eufrásio de Toledo and installed with three treatments: T1: Chemical fertilization with Simple Super Phosphate; T2: Organic fertilization with cattle manure; and T3: Witness, with four repetitions in randomized blocks. The parcels were demarcated with $2 \mathrm{~m}^{2}$ each. At 120 days, $0.50 \mathrm{~m}$ of each plot was collected to analyze the productivity, height and sample formation for bromatological analysis. It was verified by means of statistics that there was no significant influence on the different treatments.
\end{abstract}

Keywords: Cajanus Cajan, dry matter yield, crude protein.

\section{INTRODUÇÃO}

Feijão guandu é uma leguminosa que possui diversas utilidades. É uma cultura de muita importância para diversos países, principalmente os asiáticos e africanos. Esta planta é encontrada com muita frequência no Brasil principalmente nos quintais de muitas cidades do interior. Sua utilização é bastante diversificada, como planta recuperadora de solos e áreas degradadas, como forragem na alimentação de animais e também na alimentação humana. Assim possui um enorme potencial para exercer múltiplas funções nos sistemas de produção agrícola; com fixação de nitrogênio nos solos, além de gerar produtos de elevado valor biológico para melhoria do meio ambiente. Por seu valor nutritivo pode ser amplamente usado na alimentação humana.

Esta forrageira pode ser administrada de diferentes maneiras para os animais: a) para pastejo livre; b) para pastejo controlado em bancos de proteínas; c) fornecido em cochos; d) desidratado na forma de feno (SEIFFERT \& THIAGO, 1983). 
Sua implantação implica em um baixo investimento e pode ser consorciado com uma gramínea utilizada para obtenção de alimentação volumosa de melhor qualidade nutricional na busca de economicidade na produção animal.

Considerada um alimento, adubações podem ser aplicadas principalmente em solos com baixa fertilidade. Isso implica no ganho na produção dessa forrageira e na reforma da área em geral. Pode ser uma alternativa a utilização do adubo orgânico pela facilidade no acesso e um baixo custo, pois o produtor poderá utilizar estercos das vacas presentes no seu ambiente agrícola e aplicá-los na cultura.

O presente trabalho tem o objetivo de analisar a produtividade, a altura e a composição bromatológica da cultura do feijão guandu com adubação química e orgânica.

\section{MATERIAL E MÉTODOS}

O experimento foi realizado em uma área de projetos, situado na Etec Prof. Dr. António Eufrásio de Toledo - antigo Colégio Agrícola, em Presidente Prudente/SP, latitude $\left(22^{\circ} 10{ }^{\prime} 30,48^{\circ} \mathrm{S}\right)$; longitude $\left(51^{\circ} 22^{\prime} 38,30^{\circ} \mathrm{O}\right)$; e altitude $(485 \mathrm{~m})$; no período de maio de 2017 a outubro de 2017. O clima tem verões quentes e invernos secos. O solo é classificado como argissolo vermelho-amarelo, eutrófico, de textura arenosa/média (Santos et al., 1999).

A área utilizada no presente experimento vinha sendo cultivada com outras leguminosas durante as aulas práticas dos cursos oferecidos pela unidade de ensino.

Antes da implantação do experimento foi coletada a amostra de solo para caracterização dos seus atributos químicos. (Tabela 1 )

Tabela 1. Análise de solo

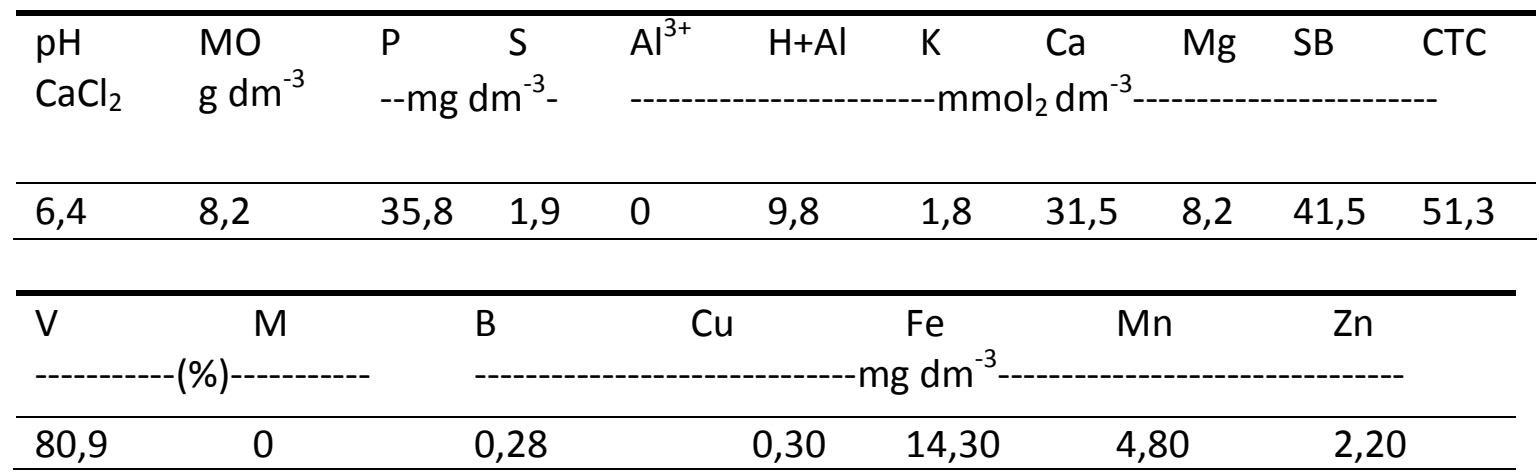

Fonte: Autores, 2017

O experimento instalado com três tratamentos: T1: Adubação química com Super Fosfato Simples; T2: Adubação Orgânica com Esterco de bovinos; e T3: Testemunha, com quatro repetições em blocos casualizados. As parcelas foram demarcadas com $2 \mathrm{~m}^{2}$ cada.

Utilizou-se a cultivar de feijão guandu (Cajanus cajan cv. BRS Mandarim), instalando-se o projeto com seu plantio no mês de maio.

A aplicação dos adubos foi feita em área total, na dosagem de $111,11 \mathrm{~kg} / \mathrm{ha}$ de Super Fosfato Simples e $10000 \mathrm{~kg} / \mathrm{ha}$ de esterco de bovinos. O presente experimento também contou com 12 plantas por $\mathrm{m} /$ linear, utilizando uma profundidade de plantio equivalente a $3 \mathrm{~cm}$ e um espaçamento entre linhas de $50 \mathrm{~cm}$.

Nos primeiros dias de desenvolvimento da cultura, foram feitas irrigações para auxiliar o crescimento inicial da cultura. As quantidades distribuídas por cada aspersor foram de 1,700 litros/hora, totalizando no período $150 \mathrm{~mm}$.

Os efeitos das adubações foram analisados medindo-se matéria verde, matéria seca, altura das plantas e o teor de proteína bruta na média de cada tratamento. Logo os dados obtidos foram avaliados por média. 


\section{RESULTADOS E DISCUSSÃO}

No presente experimento verificou-se melhor desempenho de produção de matéria verde (MV) e matéria seca (MS) no tratamento 3, que não utilizou nenhum tipo de adubação (tabela 2). Tal resultado deve-se ao fato da área ser equilibrada quimicamente, pela repetição de culturas leguminosas na área, demonstrando não haver necessidade de adubação extra no plantio de feijão guandu nas condições de realização da pesquisa.

Tabela 2. Médias MV e MS.

\begin{tabular}{ccc}
\hline TRATAMENTOS & MV & MS \\
\hline T1 & $15,34 \mathrm{~T} / \mathrm{ha}$ & $4,74 \mathrm{~T} / \mathrm{ha}$ \\
T2 & $14,34 \mathrm{~T} / \mathrm{ha}$ & $4,09 \mathrm{~T} / \mathrm{ha}$ \\
T3 & $17,09 \mathrm{~T} / \mathrm{ha}$ & $5,29 \mathrm{~T} / \mathrm{ha}$
\end{tabular}

Fonte: Autores, 2017

Entretanto, o tratamento 1 apresentou maior altura de planta (tabela 3), o que demonstra que a adubação química libera nutrientes com maior rapidez, promovendo o crescimento mais acelerado da cultura. Importante salientar que as plantas avaliadas já estavam em seu estágio máximo de crescimento para produção de forragem, pois sua tendência a partir dos 120 dias é a produção de grãos.

Tabela 3. Altura de plantas.

\begin{tabular}{cc}
\hline TRATAMENTOS & ALTURA \\
\hline T1 & $1,80 \mathrm{~m}$ \\
T2 & $1,66 \mathrm{~m}$ \\
T3 & $1,77 \mathrm{~m}$ \\
\hline
\end{tabular}

Fonte: Autores, 2017

Na tabela 4 observam-se os valores de proteína bruta (PB) para os três tratamentos, sendo que os tratamentos 1e 2, com adubação apresentam superioridade frente à testemunha, indicando que a adição de adubo favorece o metabolismo da cultura, melhorando sua composição bromatológica.

Tabela 4. Proteína Bruta.

Fonte: Autores, 2017

\begin{tabular}{cc}
\hline TRATAMENTOS & PB\% \\
\hline T1 & $21,64 \%$ \\
T2 & $21,20 \%$ \\
T3 & $19,21 \%$ \\
\hline
\end{tabular}

Não houve influência significativa nos diferentes tratamentos, de acordo com a tabela 5. Os cálculos das médias estão expostos na tabela 6 . 
Tabela 5. Valores de $\mathrm{F}$ calculados pela análise de variância para as avaliações de matéria verde (MV), matéria seca (MS) e altura do feijão guandu em função dos tratamentos aplicados.

\begin{tabular}{cccc}
\hline & MV & MS & Altura \\
\hline Tratamentos & 1,767 ns & 2,818 ns & 0,945 ns \\
\hline $\mathbf{C V}(\%)$ & 13,14 & 14,11 & 8,53 \\
& & & \\
\hline
\end{tabular}

${ }^{\text {ns }}$ não significativo.

Fonte: Autores, 2017

Tabela 6. Quantidade de matéria verde (MV), matéria seca (MS) e altura do feijão guandu em função dos tratamentos aplicados.

\begin{tabular}{ccccc}
\hline Tratamentos & MV & MS & Altura \\
\hline T 1 & & $\mathbf{( k g )}$ & & (m) \\
\hline T 2 & $0,385 \mathrm{a}$ & $0,115 \mathrm{a}$ & $1,80 \mathrm{a}$ \\
T 3 & $0,360 \mathrm{a}$ & $0,105 \mathrm{a}$ & $1,66 \mathrm{a}$ \\
\hline
\end{tabular}

As médias seguidas pela mesma letra na coluna não diferem estatisticamente entre si pelo teste de Tukey ao nível de $5 \%$ de probabilidade.

Fonte: Autores, 2017

\section{CONCLUSÕES}

Verificou-se por meio de estatística que não houve influência significativa nos diferentes tratamentos. Tal resultado deve-se ao fato da área utilizada para o experimento estar equilibrada, pois na área foram cultivados adubos verdes (leguminosas) por mais de uma safra.

\section{REFERÊNCIAS}

AGRO IPE SHOPPING AGROPECUÁRIO. Cajanus cajan cv. Caqui. Disponível em: <http://www.agroipe.com.br/Detalhe.aspx?codProduto=24>. Acessado em 24 de agosto de 2017.

AKINOLA, J. O.; WHITEMAN, P.C. \& WALLIS, E.S. The agronomy of pigeonpea (Cajanus cajan). Hurley, Commonwealth Bureau of Pastures and Field Crops, 1975. (CAB Review series, 1).

ALCÂNTARA, F.A.; FURTINI NETO, A.E.; PAULA, M.B.; MESQUITA, H.A.; MUNIZ, J.A. Adubação verde na recuperação da fertilidade de um Latossolo vermelho-escuro degradado. Pesquisa Agropecuária Brasileira, Brasília, v. 35, p. 277-288, 2000. https://doi.org/10.1590/S0100$\underline{204 X 2000000200006}$

AZEVEDO, R.L; RIBEIRO, G.T.; AZEVEDO, L.L. Feijão Guandu: Uma Planta Multiuso, v.3, n 2, p. 2, 2007.

BELTRAME, T.P.; RODRIGUES, E. Feijão guandu (Cajanus cajan (L.) Millsp.) na restauração de florestas tropicais. Semina: Ciências Agrárias, Londrina, v. 28, n. 1, p. 19-28, jan./mar. 2007. https://doi.org/10.5433/1679-0359.2007v28n1p19

BLAISE, D.; SINGH, J.V.; BONDE, A.N.; TEKALE, K.U. \& MAYEE, C.D. Effects of farmyard manure and fertilizers on yield, fibre quality and nutrient balance of rainfed cotton (Gossipium hirsutum). Biores. Technol., 96:345-349, 2005. https://doi.org/10.1016/j.biortech.2004.03.008

BONAMIGO, L.A. Recuperação de pastagens com guandu em sistema de plantio direto. Informações Agronômicas no 88, 8 p., 1999, (Encarte Técnico Potafos). 
CARDOSO, A. I. I. ; HIRAKI, H. 2001. Avaliação de doses e épocas de aplicação de nitrato de cálcio em cobertura na cultura do rabanete. Revista Horticultura Brasileira, Brasília, DF; v. 19, n. 3, p. 328-331. https://doi.org/10.1590/S0102-05362001000300007

CARDOSO, A. I. I. , HIRAKI, H. Avaliação do efeito de doses e aplicação de nitrogênio em cobertura na cultura do rabanete. In; CONGRESSO BRASILEIRO DE OLERICULTURA, 40, 2000, São Pedro, SP. Anais..., São Pedro, 2000, p.784 - 786.

CRUZ, V.C. Bromatologia aplicada à produção animal. (Unesp, 2017). Disponível em: <file:///E:/2\%20SEMESTRE/TCC/GUANDU/Documentos/Análise\%20Bromatológica.pdf>. Acessado em agosto de 2017.

DURIGON, R.; CERETTA, C. A.; BASSO, C. J.; BARCELLOS, L. A. R.; PAVINATO, P.S. Produção de forragem em pastagem natural com o uso de esterco líquido de suínos. Revista Brasileira de Ciência do Solo, Campinas, v. 26, p. 983-992, 2002. https://doi.org/10.1590/S0100$\underline{06832002000400016}$

EL-DESUKI, M. et al. Effect of plant density and nitrogen application on the growth, yield and quality of radish (Raphanus sativus L.). J.Agron., v.4, p.225 - 229, 2005 https://doi.org/10.3923/ja.2005.225.229

EMPRESA BRASILEIRA DE PESQUISA AGROPECUÁRIA. Centro de Pesquisa Agropecuária dos Cerrados, Planaltina-DF. Rel. téc. Anu. Cerrados v.5. 1981.190p.

FABICHAK, L., 2005. Pomar e horta caseiros. Livraria Nobel S.A, p. 130.

FARIA, S.M.; CAMPELLO, E.F.C. Algumas espécies de leguminosas fixadoras de nitrogênio recomendadas para revegetação de áreas degradadas. Seropédica: Embrapa- Agrobiologia, 2000. 8 p. (Recomendação Técnica, 7).

FERREIRA, C.J.; ZAMBON, F.R.A. Análise dos preços de rabanete no Estado de São Paulo. Horticultura Brasileira, Brasília, v.22, n.2, 2004 (suplemento, CD-Rom).

FILGUEIRA, F. A. R. Novo manual de olericultura: Agrotecnologia moderna na produção e comercialização de hortaliças. Viçosa-MG: UFV, 2008. 421 p.

FUNDAÇÃO CARGILL. Campinas. Adubação orgânica, adubação verde e rotação de culturas no estado de São Paulo. Campinas, 1983. 138p.

GRINDI, E.; FURLAN, M.; ANDRADE, N. Bovino cultura leiteira pastagem. Ficha pedagógica, p. 26, 2001.

HEINRICHS, R.; VITTI, G. C.; MOREIRA, A.; FIGUEIREDO, P. A. M. de; FANCELLI, A. L.; CORAZZA, E. J. Características químicas de solo e rendimento de fitomassa de adubos verdes e de grãos de milho, decorrente do cultivo consorciado. Revista Brasileira de Ciência do Solo, Viçosa, MG, v. 29, n. 1, p. 71-79, jan. / fev. 2005.

HERRERA, P.G.; LOTERO, C.J. \& CROWDER, L.V. Cutting frequency with tropical forage legumes. Agriculture Tropical, 22: 473-483, 1976. 
HOFFMANN, I.; GERLING, D.; KYIOGWOM, U.B. \& MANÉ-BIELFELDT, A. Farmers management strategies to maintain soil fertility in a remote area in northwest Nigeria. Agric., Ecosys. Environ. 86:263-275, 2001. https://doi.org/10.1016/S0167-8809(00)00288-7

HOLANDA, J.S. Esterco de curral: Composição, preservação e adubação. Natal, EMPARN, 1990. 69p. (Documentos, 17)

IBAMA - INSTITUTO BRASILEIRO DO MEIO AMBIENTE E DOS RECURSOS NATURAIS RENOVÁVEIS. Manual de recuperação de áreas degradadas pela mineração: técnicas de revegetação. Brasília: IBAMA, 1990. 96p.

LEITE, I.C. Estudos ecológicos de Raphanus sativus L. cv. Crimson Giant no efeito do comportamento térmico do solo. 1976. 122f. Monografia (Trabalho de Graduação em Agronomia) - Faculdade de Ciências Agrárias e Veterinárias, Universidade Estadual Paulista, Jaboticabal, 1976.

MACEDO, M.C.M.; ZIMMER, A.H.; KICHEL, A.N. Degradação e alternativas de recuperação e renovação de pastagens. Campo Grande: EMBRAPA-CNPGC, 2000, 4p. (Comunicado Técnico 62).

MATSUDA. Cajanus cajan cv. Caqui. Disponível em: http://www.matsuda.com.br/Matsuda/Web/sementes/Default.aspx?varSegmento=Sementes\&id produto=I10110117252577\&lang=pt-BR>. Acessado em 29 de agosto de 2017.

MINAMI, K.; TESSARIOLI NETTO, J. Rabanete: Cultura rápida, para temperaturas amenas e solos areno-argiloso. Piracicaba: ESALQ, 1997. 27p. (Série Produtor Rural, 4).

NASCIMENTO, J.T.; SILVA, I.F. Avaliação quantitativa e qualitativa da fitomasa de leguminosas para o uso como cobertura de solos. Ciência Rural, Santa Maria, v. 34, n. 3, p. 947-949, 2004. https://doi.org/10.1590/S0103-84782004000300047

NENE, Y.L.; SHEILA, V.K. Pigeonpea: geography and importance. In: NENE, Y.L.; HALL, S.D.; SHEILA, V.K (Eds.). The Pigeonpea. Cambridge: CAB International/ ICRISAT, 1990. p.1- 14.

NUNES, H. V.; SILVA, I. de F. da; BRUNO, R. de L. A.; BARROS, D. I.; PEREIRA, W. E. Influência de sistemas de culturas, mucuna preta e adubação mineral sobre a qualidade fisiológica de sementes de milho. Revista Brasileira de Sementes, Pelotas, v. 28, n. 3, p. 6-12, dez. 2006. https://doi.org/10.1590/S0101-31222006000300002

OLIVEIRA, F. R. A.; OLIVEIRA, F. A.; MEDEIROS, J. F.; SOUSA, V. F. L.; FREIRE, A. G. Interação entre salinidade e fósforo na cultura do rabanete. Revista Ciência Agronômica, v.41, n.4, p.519-526, 2010. https://doi.org/10.1590/S1806-66902010000400003

OLIVEIRA, F. N. S.; LIMA, A.A.C.; COSTA, J. B. A. Adubação verde: alternativa para os solos arenosos do Nordeste. Comunicado técnico Embrapa, no 24, dez./98, p.1-3.

PARBEY, D.B. Pasture and folder crop plants introductions at Kimberley Research Station, W. Austrália 1963-1964. L. Perenial legumes. Melbourne, CSIRO, 1967 (CSIRO, Memoir, 6716).

PAULO, E.M; BERTON, R.S.; CAVICHIOLI, J.C.; KASAI, F.S. Produtividade do cafeeiro Mundo Novo enxertado e submetido à adubação verde antes e após a recepa. Bragantia, v. 65, n. 1, p. 115, 2006. https://doi.org/10.1590/S0006-87052006000100015 
PELEGRINI, R.; DINARDI, A.L.; FORMAGI, V. M.; CONEGLIAN, C. M. R; BRITO, N. N.; DRAGONI SOBRINHO, G.; TONSO, S. Fitorremediação. In: III Fórum de Estudos Contábeis, 2003, Rio Claro. III Fórum de Estudos Contábeis, 2003. Disponível em: <http://www.ceset.unicamp.br/Ite/Artigos/3fec2407.pdf>. Acessado em julho de 2007.

PEREIRA, J. O feijão guandu: uma opção para a agropecuária brasileira. EMBRAPA- CPAC, v. 1, n. 20, pg. 11, 1985.

PIRES,F.R.; PROCÓPIO,S.O.; SOUZA,C. M.; SANTOS, J. B.; SILVA,G.P. Adubos verdes na fitorremediação de solos contaminados com o herbicida tebuthiuron. Mossoró, Caatinga, v.19, n.1, p.92-97, 2006.

PITTENGER, Dennis R. Retail Garden Center Manual. Edição ilustrada. ANR Publications, ISBN 9781-879906-74-7. 2006.

QUADROS, D.; VALLADARES, R.; REGIS, U. 2007. APROVEITAMENTO DOS DEJETOS DE CAPRINOS E OVINOS NA GERAÇÃO DE ENERGIA RENOVÁVEL E PRESERVAÇÃO DO MEIO AMBIENTE. Universidade do Estado da Bahia - Núcleo de Estudos e Pesquisas em Produção Animal, BA; p. 2.

RAO, M. R.; MATHUVA, M. N. Legumes for improving maize yields and income in semi-arid Kenya. Agriculture, Ecosystems and Environment, Amsterdam, v. 78, n. 2, p. 123-137, Apr. 2000. https://doi.org/10.1016/S0167-8809(99)00125-5

RAIJ, B. van; CANTARELLA, H.; QUAGGIO, J.A.; FURLANI, A.M.C. Recomendações de Adubação e Calagem para o Estado de São Paulo, 2 ed. rev. ampl. Campinas, Instituto Agronômico \& Fundação IAC, 1997. 285p. (Boletim Técnico, 100)

RODRIGUES FILHO, F. S.O.; GERIN, M. A. N.; FEITOSA,C. T.; IGUE, T.; SANTOS, R. R. Adubação verde e orgânica para o cultivo do amendoim (Arachis hypogaea L.). Scientia Agricola, Piracicaba, v. 53, n. 1, p. 88-93, 1996. https://doi.org/10.1590/S0103-90161996000100013

SALAZAR, F.J.; CHADWICK, D.; PAIN, B.F.; HATCH, D. \& OWEN, E. Nitrogen budgets for three cropping systems fertilised with cattle manure. Biores. Technol., 96:235-245, 2005. https://doi.org/10.1016/j.biortech.2004.05.013

SANTIGO, A.D.; ROSSETTO, R. Adubação Orgânica.Disponível em: <http://www.agencia.cnptia.embrapa.br/gestor/canadeacucar/arvore/CONTAG01_37_71120051 6717.html>. Acesso em: 18 mai. 2017.

SANTOS, C. A. F.; MENEZES, E. A.; ARAUJO, F. P. Introdução, coleta e caracterização de recursos genéticos de guandu para produção de grãos e forragem. In: Manoel Abílio de Queiroz; Clara Oliveira Goedert; Semíramis Rabelo Ramalho Ramos. (Org.). Recursos genéticos e melhoramento de plantas para o Nordeste. 1.0 ed. Petrolina: Embrapa Semi-Árido, 1999, v. online.

SEIFFERT, N.F. \& SALERNO, A.R. Guandu: leguminosa para a pequena propriedade. Florianópolis, EMPASC, 1986. 5p. (EMPASC. Comunicado Técnico, 103).

SEIFFERT, N.F.; THIAGO, L. R. L. S. Legumineira cultura forrageira para produção de proteína: guandu (Cajanus cajan). EMBRAPA-CNPGC, 52p. 1983. (Circular Técnica 13). 
VAN der MAESEN, L. J. G. Origin, History and Taxonomy of Pigeonpea. In: Pigeonpeas. CAB International/ International Crops Research Insitute for the Semi-Arid Tropics, Oxford: 15- 46, 1990.

WILLEY, P.C. \& MORTON, B.W. \& NATARAJAN, M. Tradicional cropping systems with pigeonpea and their omproviment. In: INTERNATIONAL WORKSHOP ON PIGEONPEAS, Patancheru, 1980. Proceedinga. Andhira Pradesh, ICRISAT, 1980. v. 1, p. 11-25.

WOLF SEEDS. Descrição da semente. Disponível em: <http://www.wolfseeds.com/produtos/leguminosas/feijao-guandu/>. Acessado em 23 de agosto de 2017. p. 